DEMOGRAPHIC RESEARCH

VOLUME 40, ARTICLE 16, PAGES 417-430 PUBLISHED 26 FEBRUARY 2019

http://www.demographic-research.org/Volumes/Vol40/16/

DOI: $\quad$ 10.4054/DemRes.2019.40.16

Descriptive Finding

\title{
The association between neonatal death and facility birth in regions of India
}

\section{Diane Coffey}

(C) 2019 Diane Coffey.

This open-access work is published under the terms of the Creative Commons Attribution 3.0 Germany (CC BY 3.0 DE), which permits use, reproduction, and distribution in any medium, provided the original author(s) and source are given credit.

See https://creativecommons.org/licenses/by/3.0/de/legalcode 


\section{Contents}

$\begin{array}{lll}1 & \text { Introduction } & 418\end{array}$

$2 \quad$ Data and methods $\quad 419$

$\begin{array}{lll}2.1 & \text { Data } & 419\end{array}$

$\begin{array}{ll}2.1 .1 & \text { Dependent variable }\end{array}$

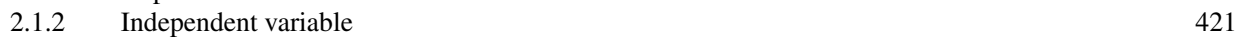

2.1.3 Control variables $\quad 423$

2.2 Methods 423

$3 \quad$ Results 426

3.1 Association between neonatal death and facility birth, by region $\quad 426$

3.2 Within-village comparisons, by region 426

4 Discussion $\quad 428$

$\begin{array}{lr}\text { References } & 429\end{array}$ 


\title{
The association between neonatal death and facility birth in regions of India
}

\author{
Diane Coffey ${ }^{1}$
}

\begin{abstract}
BACKGROUND

Reducing neonatal mortality in India is critical to achieving the 2030 Sustainable Development Goal of a global neonatal mortality rate (NNM) of no more than 12 per 1,000. Policy efforts to reduce India's NNM, including a large-scale conditional cash transfer program, have focused on promoting birth in health facilities, rather than at home. Between 2005 and 2015, the percentage of facility births doubled, from $40 \%$ to $80 \%$.
\end{abstract}

\section{OBJECTIVE}

We assess evidence for the hypothesis that facility births reduce NNM by using new data from the National Family Health Survey, 2015-2016.

\section{METHODS}

We analyze the association between neonatal death and facility birth at the region level, using ordinary least squares (OLS) linear probability models with fixed effects for the primary sampling unit, as well as child, mother, and household-level controls.

\section{RESULTS}

For babies born outside of Uttar Pradesh and Bihar, facility birth is robustly associated with neonatal survival. The controlled association between facility birth and neonatal survival is 7 per 1,000 in the east region (West Bengal, Assam, Jharkhand, Odisha) and 13 per 1,000 in the central region (Madhya Pradesh and Chhattisgarh). In Uttar Pradesh and Bihar, however, being born in a health facility appears to confer no neonatal survival advantage.

\section{CONTRIBUTION}

Documenting the lack of an association between facility birth and neonatal death in Uttar Pradesh and Bihar is important because these states collectively contribute 43\% of India's

\footnotetext{
${ }^{1}$ Population Research Center and Department of Sociology, University of Texas, Austin, USA; r.i.c.e - Research Institute for Compassionate Economics, Amston, USA; Indian Statistical Institute, Delhi Centre, New Delhi, India. Email: coffey@utexas.edu.
} 
Coffey: The association between neonatal death and facility birth in regions of India

NNM. These findings suggest the need for future research to investigate whether and how the quality of maternal and newborn care in health facilities differs across regions.

\section{Introduction}

The United Nations' Sustainable Development Goal 3 aims to reduce global neonatal mortality (NNM) to 12 deaths per 1,000 live births by 2030. Reducing NNM in India is critical to achieving this goal because it is home to $27 \%$ of neonatal deaths but only $19 \%$ of births. India contributes more neonatal deaths than any other country. Its national NNM of 30 per 1,000 in 2015 (IIPS and ICF 2017) masks wide variation across places. Among states with more than 25 million people, Uttar Pradesh had the highest NNM at 45 per 1,000, and Kerala had the lowest at 4 per 1,000. India's state-level variation in NNM is similar to the country-level variation in NNM that exists on a global scale. According to the 2015 World Development Indicators, the Central African Republic had the second highest NNM in the world at 43 per 1,000, and the United States had an NNM of 4 per 1,000 (World Bank Group 2015).

India's high NNM is particularly surprising in light of a recent, dramatic increase in the fraction of births that occur in health facilities, rather than at home. In 2005, about $40 \%$ of births took place in health facilities; by 2015 , this figure was $80 \%$. The increase in facility births was in part due to a large-scale, conditional cash transfer program called Janani Surkasha Yojana (JSY). JSY was launched in 2005 as part of the central government's new National Rural Health Mission (NRHM). JSY, which means Safe Motherhood Scheme, pays local health workers to accompany women to deliver in health facilities. Women who deliver in health facilities also receive a cash payment.

A key assumption of the JSY program, and of much of the Indian government's maternal and child health strategy, is that shifting births from homes to health facilities will reduce NNM (Rao 2017). However, causal analysis to test the validity of this assumption is difficult; it is not possible to randomly assign place of birth.

Can descriptive analysis help deepen our understanding of the relationship between NNM and facility birth? The uncontrolled association, at the individual level, between neonatal death and facility birth is likely to be confounded by a number of factors. For instance, in India's National Family Health Survey (NFHS)-3, collected before JSY was implemented in 2005, there was little difference in neonatal survival between babies born at home and those born in health facilities. The lack of association could have had many possible explanations, among them that health facilities were ineffective at promoting neonatal health, or that the mothers who delivered in health facilities were a mix of privileged women (whose neonates may have survived regardless of where they were born) and women with labor complications (who may often have arrived too late to be helped 
by the health facility). Considering the large variation in quality of public services across regions and states of India (Drèze and Sen 2013), it is also possible that the true effect of hospital birth on neonatal survival was heterogenous.

In this descriptive paper, I use the latest-available data from the National Family Health Survey, 2015-2016 (NFHS-4) to advance understanding of the association between neonatal survival and facility birth. The weighted, uncontrolled, all-India association between neonatal survival and facility birth was 12 per 1,000. That is, NNM was 12 per 1,000 lower among children born in health facilities than among children born at home. The analysis that follows unpacks this association at the region level, showing that it is robust to controls for possible omitted factors in some regions - particularly in east and central India - and not statistically significantly different from zero in others, including in Uttar Pradesh and Bihar, two states that together contribute about $43 \%$ of India's NNM.

\section{Data and methods}

\subsection{Data}

NFHS-4, conducted between January 2015 and December 2016 is India's most recent Demographic and Health Survey (DHS). The prior DHS round, the NFHS-3, was conducted in 2005-2006. Both are nationally representative, multistage, clustered sample surveys. This paper's analyses focus on the 2015-2016 survey; summary statistics from both surveys are used to identify recent trends.

States with populations of over 25 million at the time of the 2011 Census are included in the analyses. These states are home to approximately $95 \%$ of the population of India. States are grouped into regions based on the NFHS-4's regional classifications (IIPS and ICF 2017). Table 1 shows the division of states into regions. Uttar Pradesh and Bihar are treated as their own region, the focus region, because these geographically contiguous states have high NNM and contribute a disproportionate number of neonatal deaths. 
Coffey: The association between neonatal death and facility birth in regions of India

Table 1: $\quad$ Place of birth and NNM in Indian states, 2005-2006 and 2015-2016

\begin{tabular}{|c|c|c|c|c|c|c|c|c|c|c|}
\hline \multirow[b]{3}{*}{ Region and state } & \multirow{2}{*}{\multicolumn{2}{|c|}{$\begin{array}{c}\text { Fraction } \\
\text { Home birth }^{\mathrm{a}}\end{array}$}} & \multirow{2}{*}{\multicolumn{2}{|c|}{$\begin{array}{c}\text { Fraction } \\
\text { Facility birth }^{\mathrm{a}}\end{array}$}} & \multirow{2}{*}{\multicolumn{2}{|c|}{$\mathrm{NNM}^{\mathrm{b}}$}} & \multicolumn{4}{|c|}{ Fraction of India's total ${ }^{c}$} \\
\hline & & & & & & & \multicolumn{2}{|c|}{ Births } & \multicolumn{2}{|c|}{ Neonatal deaths } \\
\hline & 05-06 & $15-16$ & 05-06 & $15-16$ & 05-06 & $15-16$ & 05-06 & $15-16$ & $05-06$ & $15-16$ \\
\hline Focus states & 0.80 & 0.34 & 0.20 & 0.66 & 45 & 42 & 0.32 & 0.30 & 0.37 & 0.43 \\
\hline Uttar Pradesh & 0.79 & 0.32 & 0.21 & 0.68 & 48 & 45 & 0.21 & 0.18 & 0.25 & 0.27 \\
\hline Bihar & 0.80 & 0.36 & 0.20 & 0.64 & 40 & 37 & 0.11 & 0.13 & 0.11 & 0.16 \\
\hline Central & 0.77 & 0.20 & 0.23 & 0.80 & 46 & 38 & 0.09 & 0.10 & 0.11 & 0.12 \\
\hline Madhya Pradesh & 0.74 & 0.19 & 0.26 & 0.81 & 45 & 37 & 0.07 & 0.07 & 0.08 & 0.08 \\
\hline Chhattisgarh & 0.86 & 0.30 & 0.14 & 0.70 & 51 & 42 & 0.02 & 0.02 & 0.03 & 0.03 \\
\hline East & 0.67 & 0.26 & 0.33 & 0.74 & 43 & 27 & 0.17 & 0.17 & 0.18 & 0.14 \\
\hline West Bengal & 0.58 & 0.24 & 0.42 & 0.76 & 38 & 22 & 0.07 & 0.07 & 0.07 & 0.05 \\
\hline Jharkhand & 0.82 & 0.38 & 0.18 & 0.62 & 49 & 33 & 0.03 & 0.03 & 0.04 & 0.03 \\
\hline Assam & 0.77 & 0.29 & 0.23 & 0.71 & 46 & 33 & 0.03 & 0.02 & 0.03 & 0.03 \\
\hline Odisha & 0.64 & 0.14 & 0.36 & 0.86 & 45 & 28 & 0.03 & 0.03 & 0.04 & 0.03 \\
\hline West & 0.40 & 0.10 & 0.60 & 0.90 & 32 & 20 & 0.13 & 0.12 & 0.10 & 0.08 \\
\hline Maharashtra & 0.35 & 0.10 & 0.65 & 0.90 & 32 & 16 & 0.08 & 0.09 & 0.06 & 0.05 \\
\hline Gujarat & 0.47 & 0.11 & 0.53 & 0.89 & 34 & 27 & 0.05 & 0.04 & 0.04 & 0.04 \\
\hline South & 0.26 & 0.05 & 0.74 & 0.95 & 29 & 17 & 0.16 & 0.18 & 0.12 & 0.10 \\
\hline $\begin{array}{l}\text { Andhra Pradesh } \\
\text { and Telegana }\end{array}$ & 0.35 & 0.08 & 0.65 & 0.92 & 40 & 22 & 0.06 & 0.06 & 0.06 & 0.05 \\
\hline Tamil Nadu & 0.12 & 0.01 & 0.88 & 0.99 & 19 & 14 & 0.04 & 0.06 & 0.02 & 0.03 \\
\hline Karnataka & 0.35 & 0.06 & 0.65 & 0.94 & 29 & 19 & 0.05 & 0.04 & 0.03 & 0.03 \\
\hline Kerala & 0.01 & 0.00 & 0.99 & 1.00 & 12 & 4 & 0.02 & 0.02 & 0.01 & 0.00 \\
\hline North & 0.65 & 0.16 & 0.35 & 0.84 & 37 & 27 & 0.10 & 0.10 & 0.10 & 0.10 \\
\hline Harayana & 0.64 & 0.20 & 0.36 & 0.80 & 24 & 22 & 0.02 & 0.02 & 0.01 & 0.02 \\
\hline Punjab & 0.49 & 0.10 & 0.51 & 0.90 & 28 & 21 & 0.02 & 0.02 & 0.01 & 0.01 \\
\hline Rajasthan & 0.70 & 0.16 & 0.30 & 0.84 & 44 & 30 & 0.06 & 0.06 & 0.07 & 0.06 \\
\hline
\end{tabular}

Note: Summary statistics are shown for Indian states that had populations larger than 25 million in the 2011 Census of India. In each survey year, these states accounted for $97 \%$ of NNM in India. Estimates use survey weights provided by the NFHS. a A 'home birth' is a birth that occurred at home; a 'facility birth' is a birth that occurred in a health facility. The NFHS collected data on place of birth for each mother's last three births in the five years before the survey. ${ }^{\mathrm{b}} \mathrm{NNM}$ is neonatal mortality, the number of deaths per 1,000 live births that took place in the first month of life. NNM is computed by using the same method that is used by the DHS (see Rutstein and Rojas 2006) and uses births in the five years before the survey. ${ }^{c}$ Figures for the percentage of total births and neonatal deaths do not add to one because they use all of India in the denominator, not states with populations greater than 25 million. These figures are computed using births in the five years before the survey.

\subsubsection{Dependent variable}

The dependent variable of interest is neonatal death. It is coded as either " 0 " if the child survived the first month of life, or " 1,000 " if the child died in the first month of life. Coding death as " 1,000 " rather than " 1 " for the regression analysis does not change 
the results; it simply changes the scale of regression coefficients so that they are easy to interpret as effects on "per 1,000" rates, which is how NNM is normally published. Children born in the five years before the survey are included in the sample, except for children who were born less than a month before the survey, as their neonatal survival status is unknown.

Table 1 provides state and region-level estimates of NNM that are computed using the method that the DHS uses to compute published summary statistics (Rutstein and Rojas 2006). Table 1 also provides information about the percentage of India's births and neonatal deaths that occur in each region and state. It shows that the states of Uttar Pradesh and Bihar contribute disproportionately to neonatal death relative to births.

\subsubsection{Independent variable}

The independent variable of interest is an indicator that is equal to " 1 " if the child's birth took place in a health facility (public or private) and "0" if the birth took place at home. The NFHS-4 collected information on place of birth for live births that occurred in the five years before the survey. ${ }^{2}$ Table 1 summarizes state and region-level variation in the fraction of births that took place in health facilities. It also includes statistics from the NFHS-3 for comparison.

\footnotetext{
${ }^{2}$ For mothers who had more than three live births in the five years before the survey, the NFHS collected place of birth for the last three births. In the states we analyze, $0.3 \%$ of births in the last five years are missing information on place of birth.
} 
Coffey: The association between neonatal death and facility birth in regions of India

\section{Original figure removed at the author's request.}




\subsubsection{Control variables}

Table 1 shows large variation in NNM across places in India, which suggests that NNM may be influenced by a number of variables other than facility birth, such as the disease environment, underlying maternal health, levels of gender empowerment, cultural practices, and access to prenatal services. Our primary strategy for controlling for these and other possible confounding variables is to use fixed effects for a child's primary sampling unit (PSU). PSUs are villages in rural areas and census enumeration blocks in urban areas (IIPS and ICF 2017). Children in the same PSUs share many of the characteristics described above. The coefficient on facility birth that is produced by using a PSU-fixed effects regression is computed by averaging differences in neonatal survival between children who were born in health facilities and at home within the same PSU. PSUs in which there is no variation in place of birth do not contribute to the estimate. ${ }^{3}$

A PSU-fixed effects regression also permits child, mother, and household-level demographic and socioeconomic controls. Below, we describe the wide array of additional controls included in the model.

\subsection{Methods}

Figures 1 and 2 present the results of uncontrolled and controlled regressions respectively. Figure 1 plots coefficients and standard errors from region or state-level regressions of the following form:

$$
\text { neonatal death } h_{i}=\beta_{0}+\beta_{1}{\text { facility } \text { birth }_{i}+\epsilon_{i},}
$$

where $i$ indexes live births and $\hat{\beta}_{1}$ is the estimated coefficient of interest.

\footnotetext{
${ }^{3}$ Across the seven regions, an average of about $30 \%$ of PSUs are dropped from the high-dimensional fixed effects regression described in Equation 2 because there is only one birth in that PSU. Dropping singleton observations is useful in this context because, if they are not dropped, standard errors will be underestimated (Correia 2016).
} 
Coffey: The association between neonatal death and facility birth in regions of India

\section{Figure 1: $\quad$ Associations between NNM and facility birth, no controls,} 2015-2016

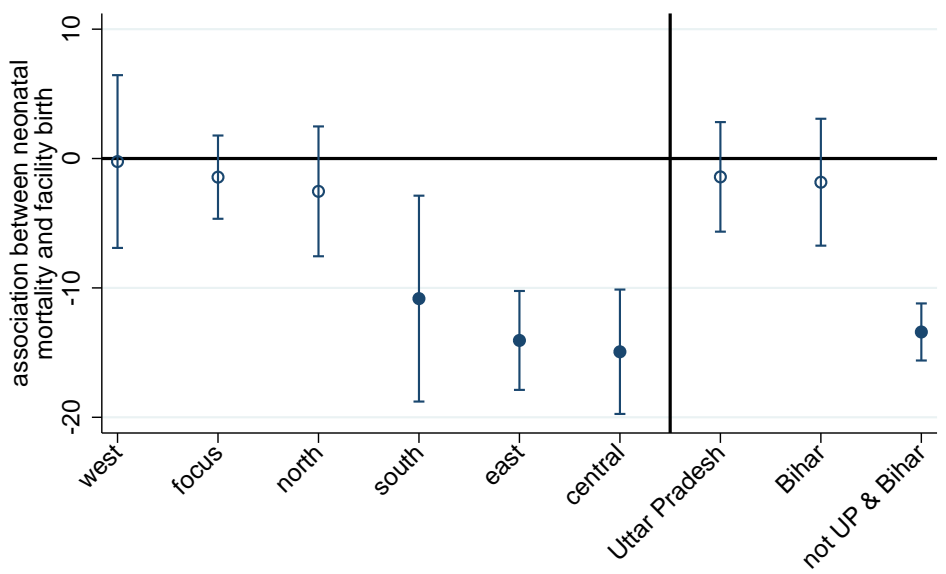

- statistically significant $\circ$ not statistically significant

Note: The figure plots OLS regression coefficients and confidence intervals (computed with standard errors clustered by PSU) from regressions of NNM on facility birth (see Equation 1) for regions and states of India. Gujarat and Maharastra compose 'west'; Uttar Pradesh and Bihar compose 'focus'; Haryana, Punjab, and Rajasthan compose 'north'; Andhra Pradesh, Telegana, Karnataka, Kerala, and Tamil Nadu compose 'south'; Orissa, West Bengal, Jharkhand, and Assam compose 'east'; and Madhya Pradesh and Chhattisgarh compose 'central.' 'Not UP \& Bihar' indicates a result that pools states in all other regions except for Uttar Pradesh and Bihar.

Figure 2 plots coefficients and standard errors from region or state-level regressions of the following form:

$$
\begin{aligned}
& \text { neonatal death }_{i p}=\beta_{0}+\beta_{1} \text { facility birth }_{i p}+\beta_{2} \text { male }_{i p}+\sum_{b=1}^{b=4^{+}} \beta_{3}^{b} \text { birth order }_{i p} \\
& +\sum_{s=1}^{s=6^{+}} \beta_{4}^{s} \text { sibsize }_{i p}+\beta_{5} \text { mother's years of education }_{i p} \\
& +\beta_{6} \text { mother's age at birth }{ }_{i p}+\beta_{7} \text { mother's age at birth }{ }_{i p}^{2} \\
& +\alpha_{p}+M_{i p} \theta+S E S_{i p} \gamma+\epsilon_{i p} \text {, }
\end{aligned}
$$

where $\alpha_{p}$ are fixed effects for child $i$ 's primary sampling unit, $p ; M_{i p}$ is a vector of fixed effects for the century month code (CMC) of the child's birth; and $S E S_{i p}$ is a large vector of indicators for household socioeconomic status. ${ }^{4}$ And male $e_{i p}$ controls for the sex of

\footnotetext{
${ }^{4}$ We include indicator variables that control for every combination of ownership of radio, television, refriger-
} 
the child; ${ }^{5}$ birth order is entered as indicator variables, ranging from 1 to $4^{+}$; and sibsize is a set of indicators for the number of children ever born to the child's mother at the time of the survey, ranging from 1 to $6^{+}$. The model also includes controls for the mother's education in years, and mother's age and age-squared (both in years) at the time of child $i$ 's birth. Any survival advantage of being born in a health facility that remains after controlling for these indicators reflects a difference that persists even after very detailed demographic, geographic, and SES information has been accounted for.

\section{Figure 2: $\quad$ Associations between NNM and facility birth, with controls, 2015-2016}

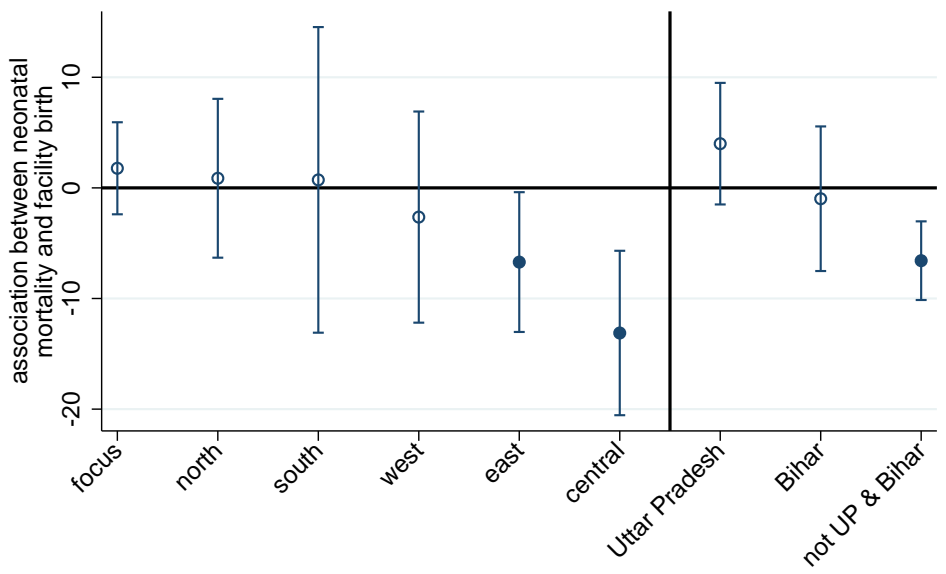

- statistically significant $\quad$ not statistically significant

Note: The figure plots OLS regression coefficients and confidence intervals (computed with standard errors clustered by PSU) from regressions of NNM on facility birth and controls (see Equation 2 and Section 2.2 for a description of the controls) for regions and states of India. The note for Figure 1 lists the states that correspond to each region.

ator, bicycle, motorcycle, telephone, and car, as well as type of flooring (in 15 categories), type of toilet facility (in 13 categories), household electrification, and mother's educational attainment (in six categories).

${ }^{5}$ If we instead run the regressions separately by sex, we get a similar pattern of results. Results are more attenuated for girls, who are biologically more robust than boys. The only surprising result is that in the northwest region, facility birth is statistically significantly associated with survival for girls, but not boys. 
Coffey: The association between neonatal death and facility birth in regions of India

\section{Results}

\subsection{Association between neonatal death and facility birth, by region}

Figure 1 plots coefficients and standard errors from Equation 1. It documents associations between neonatal death and facility birth, without controls, in different regions of India. In the south, east, and central regions, there is a negative association between neonatal death and facility birth. In the focus, north, and west regions, babies born in health facilities are no more likely to survive than those born at home.

\subsection{Within-village comparisons, by region}

Section 2 suggests several reasons why the coefficient on facility birth estimated by Equation 1 may be downwardly biased. Figure 2 plots coefficients on facility birth that are estimated using Equation 2, which controls for PSU fixed effects, as well as a host of child, mother, and household-level demographic and socioeconomic characteristics. For the south region, the introduction of controls attenuates the coefficient to the point that it is no longer statistically significant, suggesting that women who deliver at home in the south may be different, on average, from the majority who deliver in health facilities. ${ }^{6}$ In east and central India, in contrast, the association between neonatal death and facility birth is both negative and statistically significant, even after the introduction of this large set of controls.

Perhaps the most striking result presented in Figure 2 is given on the right side of the figure. In a pooled regression using data from all of the regions except the focus region - Uttar Pradesh and Bihar - the association between neonatal death and facility birth is negative and statistically significant. For Bihar, the coefficient is not statistically significant, but it is slightly negative. In contrast, the point estimate for Uttar Pradesh is positive, and the confidence interval on the estimate does not overlap with that for the pooled estimate for the other regions.

For each of the three places on the right side of Figure 2, Table 2 shows coefficient estimates for facility birth as well as many of the control variables included in the model described by Equation 2. The coefficient estimates underscore the importance of the controls - especially birth order and sibsize - in predicting neonatal mortality in all three places. ${ }^{7}$ Further, children whose mothers are at the extremes of the age distribution, and male children, are more likely to die neonatal deaths. However, it is noteworthy that, outside of Uttar Pradesh and Bihar, even after accounting for this wide array of child,

\footnotetext{
${ }^{6}$ Another reason why the coefficient may be attenuated in these results is that fewer births are used to identify the association in Equation 2 than Equation 1.

${ }^{7}$ See Coffey and Spears (2018) for a discussion of why birth order and sibsize are highly predictive of NNM in India.
} 
mother, and household-level demographic and socioeconomic controls, as well as PSU fixed effects, children born in a health facility face an NNM about 7 per 1,000 lower than children born at home.

Table 2: $\quad$ Predictors of neonatal mortality, 2015-2016

\begin{tabular}{|c|c|c|c|}
\hline \multirow[t]{2}{*}{ Dependent variable: } & \multicolumn{3}{|c|}{ Neonatal death $=1,000 ;$ neonatal survival $=0$} \\
\hline & Uttar Pradesh & Bihar & Other regions ${ }^{a}$ \\
\hline \multirow[t]{2}{*}{ Facility } & 3.997 & -0.979 & $-6.580^{* * *}$ \\
\hline & $(2.803)$ & (3.335) & $(1.814)$ \\
\hline \multirow[t]{2}{*}{ Male } & $11.11^{\star * *}$ & $13.99^{\star * *}$ & $11.11^{\star * *}$ \\
\hline & (2.291) & (2.568) & $(0.997)$ \\
\hline \multirow[t]{2}{*}{ Birth order 2} & $-55.61^{\star * *}$ & $-48.60^{* \star *}$ & $-44.69^{* * *}$ \\
\hline & $(4.426)$ & $(5.443)$ & $(2.011)$ \\
\hline \multirow[t]{2}{*}{ Birth order 3} & $-102.2^{* \star *}$ & $-80.23^{\star * *}$ & $-98.67^{* \star *}$ \\
\hline & (7.037) & $(8.666)$ & (3.794) \\
\hline \multirow[t]{2}{*}{ Birth order 4} & $-151.4^{* * *}$ & $-119.7^{* * *}$ & $-149.6^{* * *}$ \\
\hline & (10.38) & (12.03) & $(6.135)$ \\
\hline \multirow[t]{2}{*}{ Sibsize of 2} & $50.50^{\star \star \star}$ & $42.61^{* \star *}$ & $40.91^{\star \star \star}$ \\
\hline & $(4.743)$ & $(6.026)$ & $(2.125)$ \\
\hline \multirow[t]{2}{*}{ Sibsize of 3} & $104.6^{\star \star \star}$ & $75.20^{\star \star *}$ & $96.99^{\star * *}$ \\
\hline & (7.267) & (9.125) & (3.806) \\
\hline \multirow[t]{2}{*}{ Sibsize of 4} & $164.6^{\star * *}$ & $123.7^{\star \star *}$ & $151.7^{\star \star \star}$ \\
\hline & $(10.17)$ & (12.39) & $(6.176)$ \\
\hline \multirow[t]{2}{*}{ Sibsize of 5} & $187.1^{\star \star \star}$ & $135.4^{\star \star \star}$ & $163.5^{\star \star \star}$ \\
\hline & (12.12) & $(14.17)$ & $(7.155)$ \\
\hline \multirow[t]{2}{*}{ Sibsize of 6} & $198.3^{\star \star \star}$ & $151.6^{\star \star *}$ & $180.9^{* * *}$ \\
\hline & (12.34) & $(14.39)$ & (7.751) \\
\hline \multirow[t]{2}{*}{ Mother's education (in years) } & -2.089 & $-4.991^{*}$ & -0.339 \\
\hline & $(1.583)$ & $(1.965)$ & $(0.496)$ \\
\hline \multirow[t]{2}{*}{ Mother's age at birth } & $-7.934^{\star \star \star}$ & $-8.150^{* *}$ & $-3.678^{\star \star *}$ \\
\hline & $(2.188)$ & $(2.688)$ & $(0.985)$ \\
\hline \multirow[t]{2}{*}{ Mother's age at birth ${ }^{2}$} & $0.132^{\star * *}$ & $0.134^{\star *}$ & $0.0680^{\star * *}$ \\
\hline & $(0.0386)$ & $(0.0492)$ & $(0.0183)$ \\
\hline PSU fixed effects & $\checkmark$ & $\checkmark$ & $\checkmark$ \\
\hline CMC fixed effects & $\checkmark$ & $\checkmark$ & $\checkmark$ \\
\hline SES indicators & $\checkmark$ & $\checkmark$ & $\checkmark$ \\
\hline$n$ & 40,256 & 24,721 & 139,267 \\
\hline
\end{tabular}

Note: The table reports OLS regression coefficients and standard errors (clustered by PSU) from regressions of NNM on facility birth and controls (see Equation 2 and Section 2.2 for a description of the controls). ${ }^{*} p<0.05$, ${ }^{* *} p$ $<0.01,{ }^{* \star *} p<0.001$. "other regions" combines data for all states listed in Table 1 except for Uttar Pradesh and Bihar. 
Coffey: The association between neonatal death and facility birth in regions of India

\section{Discussion}

Considering that promoting facility birth has been the cornerstone of maternal and newborn health policy in India for much of the last decade, the finding that facility birth is uncorrelated with neonatal death in Uttar Pradesh and Bihar - which together contribute $43 \%$ of India's neonatal mortality - is concerning. It is especially concerning for the state of Uttar Pradesh, which has a 2015 neonatal mortality rate higher than every country in the world except Pakistan, and which contributes $27 \%$ of India's neonatal deaths.

The lack of an association between neonatal death and facility birth coheres with prior qualitative research which suggests that the quality of maternal and newborn care in health facilities in this region is extremely poor (Jeffery and Jeffery 2010; Coffey 2014). It also coheres with the results of Semrau et al. (2017), a randomized controlled trial of the "Better Birth" coaching program which aimed to improve the quality of maternal and newborn care in health facilities in 24 districts of Uttar Pradesh. The program, which was successful in other contexts (Kabongo et al. 2017), was intensive. It consisted of 43 daylong coaching visits to each facility over a period of eight months. Nevertheless, twelve months after the program was implemented, researchers found only modest differences in the quality of maternal and newborn care provided in intervention vs. control facilities. They found no differences in perinatal or maternal mortality, nor in major health complications following delivery. Thus, both qualitative and quantitative research provide evidence that the government's rather singular focus on promoting facility birth may be misguided in this high-mortality region.

The robust, negative association between neonatal death and facility birth in the east and central regions is, however, encouraging, and suggests that the JSY program may have had heterogenous effects. These regions saw much larger improvements in NNM in the last decade than were observed for Uttar Pradesh and Bihar. Robust associations between neonatal death and facility birth are consistent with evidence from the Million Deaths Study, which studied changes in causes of death between 2000 and 2015 in partnership with India's Sample Registration System (Fadel et al. 2017). The study found that declines in NNM came primarily from declines in birth trauma and birth asphyxia, causes of neonatal death that could plausibly be influenced by care at birth in a health facility. We note that it is puzzling that Fadel et al. (2017) find significant declines in neonatal mortality from birth asphyxia and birth trauma in Bihar and Uttar Pradesh, as well as in the central and east regions. Future research might usefully compare how delivery and postpartum care practices differ between the central and east regions and the states of Uttar Pradesh and Bihar. 


\section{References}

Coffey, D. (2014). Costs and consequences of a cash transfer for hospital births in a rural district of Uttar Pradesh, India. Social Science and Medicine 114: 89-96. doi:10.1016/ j.socscimed.2014.05.035.

Coffey, D. and Spears, D. (2018). Neonatal death in India: The effect of birth order in a context of maternal undernutrition. Paper presented at the Population Association of America Conference, Austin, USA, April 10-13, 2019.

Correia, S. (2016). Linear models with high-dimensional fixed effects: An efficient and feasible estimator [unpublished manuscript]. Washington, D.C.: Board of Governors of the Federal Reserve System.

Drèze, J. and Sen, A. (2013). An uncertain glory: India and its contradictions. Princeton: Princeton University Press.

Fadel, S.A., Rasaily, R., Awasthi, S., Begum, R., Black, R.E., Gelband, H., Gerland, P., Kumar, R., Liu, L., and Mathers, C. (2017). Changes in cause-specific neonatal and 1-59-month child mortality in India from 2000 to 2015: A nationally representative survey. The Lancet 390(10106): 1972-1980. doi:10.1016/S0140-6736(17)32162-1.

IIPS and ICF (2017). National Family Health Survey (NFHS-4) 2015-16: India. Mumbai: International Institute for Population Sciences.

Jeffery, P. and Jeffery, R. (2010). Only when the boat has started sinking: A maternal death in rural north India. Social Science and Medicine 71(10): 1711-1718. doi:10.1016/j.socscimed.2010.05.002.

Kabongo, L., Gass, J., Kivondo, B., Kara, N., Semrau, K., and Hirschhorn, L.R. (2017). Implementing the WHO Safe Childbirth Checklist: Lessons learnt on a quality improvement initiative to improve mother and newborn care at Gobabis District Hospital, Namibia. BMJ Open Quality 6(2): e000145. doi:10.1136/bmjoq-2017-000145.

Rao, S. (2017). Do we care? India's health system. New Delhi: Oxford University Press. doi:10.1093/acprof:oso/9780199469543.001.0001.

Rutstein, S.O. and Rojas, G. (2006). Guide to DHS statistics. Calverton: ORC Macro (Technical report). http://www.ophi.org.uk/wp-content/uploads/OPHI-HDCASS2012-Guide_DHS_Statistics.pdf.

Semrau, K.E., Hirschhorn, L.R., Marx Delaney, M., Singh, V.P., Saurastri, R., Sharma, N., Tuller, D.E., Firestone, R., Lipsitz, S., Dhingra-Kumar, N., Kodkany, B.S., Kumar, V., and Gawande, A.A. (2017). Outcomes of a coaching-based WHO Safe Childbirth Checklist program in India. New England Journal of Medicine 377(24): 2313-2324. doi:10.1056/NEJMoa1701075. 
Coffey: The association between neonatal death and facility birth in regions of India

World Bank Group (2015). World development indicators 2015 [electronic resource]. Washington, D.C.: World Bank Publications. https://data.worldbank.org/indicator.

\section{Acknowledgments}

I appreciate helpful suggestions from the editor, two anonymous reviewers, Dean Spears, Sangita Vyas, and Alex Weinreb. All errors are my own. This research was supported by grant P2CHD042849, Population Research Center, awarded to the Population Research Center at The University of Texas at Austin by the Eunice Kennedy Shriver National Institute of Child Health and Human Development. The content is solely the responsibility of the author and does not necessarily represent the official views of the NIH.

Correction:

On December 13, 2019, one of the original Figures was removed from the paper at the author's request. 